\title{
Penyebaran Salafi Jihadis Ke Perguruan Tinggi di Malaysia dan Dampaknya Terhadap Islamophobia
}

Amirulhakim Ahmad Nadzri' ${ }^{1}$ Rahimin Affandi Abdul Rahim², Mohd Anuar

Ramli3 ${ }^{3}$ Muhd Imran Abd Razak, Muhammad Yusri Yusof @Salleh, Paiz Hassan $^{4}$

\begin{abstract}
Abstrak
Perjalanan dalam penyebaran syiar Islam merupakan jalan yang mulia dan ia juga memerlukan kepada satu konsep iaitu pendidikan. Dalam arus semasa ini, perguruan tinggi menjadi satu medan atau tempat yang telah dimasuki penyebaran ideologi salafi jihadis yang akan membawa dampak negatif terhadap Agama Islam. Maka akhirnya akan membawa kepada penularan penyakit Islamiphobia. Penelitian ini menggunakan metodologi kepustakaan dengan menilai serta melihat penelitian orang-orang terdahulu, manuskrip serta kasus-kasus yang timbul dalam ranah masyarakat. Hasil penelitian menyimpulkan, bahwa perguruan tinggi juga menjadi tempat tersebarnya ideologi salafi jihadis yang turut menyumbang kepada Islamiphobia.
\end{abstract}

Kata Kunci: perguruan tinggi, salafi jihadis, islamiphobia

\section{Abstract}

Dissemination of Islam is an honourable act that requires a concept or medium which is education. Currently, the higher education institutions has been invated bu Salafi Jihadis ideology which impacted Islam negatively where eventually led to Islamophobic escalation. This research is conducted through literay methodology which analysing this previous research, manuscripts and casa studies that occurred within the society. This research finds that the higher education institutions has been the platform for disseminating salafi jihadis ideology which contributing to Islamophobia.

Keywords: higher education institutions, salafi jihadis, islamophobia

\section{Pendahuluan}

Pihak Perserikatan Bangsa-Bangsa (PBB) dalam "Action Plan" menangani isu ekstrimisme agama menetapkan bahwa institusi pendidikan khususnya tingkat Perguruan Tinggi adalah medium terbaik untuk melatih, menangkis atau menolak ekstrimisme agama (UNESCO, 2017). la juga turut diambil perhatian oleh semua sarjana Islam. Namun begitu, ketetapan PBB ini kurang diperhatikan secara serius oleh Institusi PerguruanTinggi baik di barat ataupun negara Islam sendiri. Hasilnya, usaha menangani isu ekstrimisme agama telah menemui jalan buntu, malah mahasiswa di perguruan tinggi juga terlibat dalam kelompok ektrimis seperti Daesh, ISIS dan sebagainya. Berdasarkan kepada latar belakang ini, penelitian ini akan mencoba menganalisis bagaimana penyebaran ideologi ektrimis seperti Daesh yang membawa

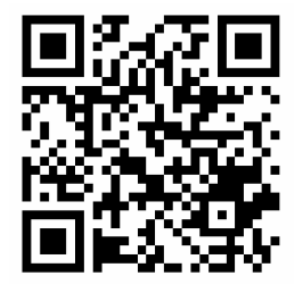

1. Dosen di Jurusan Syariah Islamiyyah, Kolej Islam As Sofa, Blok D1-5,3, Desa Permai, Taman Dato' Ahmad Razali, 68000 Ampang, Selangor Darul Ehsan. Email:

akimnadzri@gmail.com .

2. Guru Besar dalam IImu Fiqh Dan Ushul, Akademi

Pengajian Islam, Universiti Malaya, 50603 Kuala Lumpur. Email:

faqir_ila rabbih@um.edu.my

3. Dosen di jurusan Fiqh dan Ushul, Akademi Pengajian Islam, Universiti Malaya, 50603 Kuala Lumpur. Email: mohdanuar@um.edu.my

Dosen di Akademi Pengajian Islam Kontemporari (ACIS), Universiti Teknologi Mara (Perak) Kampus Seri Iskandar, 32610 Bandar Seri Iskandar, Perak.

Submitted : Juli 2018 Accepted : Juli 2018

\footnotetext{
JAS-PT

JURNAL ANALISIS SISTEM PENDIDIKAN TINGGI ISSN 2580 - 5339 eISSN $2620-5718$

Volume 2

Nomor 1

JULI 2018

Hal $27-38$
}

FORUM DOSEN INDONESIA 
aliran salafi jihadis ke perguruan tinggi dan ia menyumbang kepada Islamiphobia di duni barat.

\section{Premis asas}

Bagi penulis, kesalahan terbesar Salafi Jihadis adalah memberi citra negatif Islam kepada masyarakat dunia. la secara langsung menyumbang kepada pengukuhan teori Clash Of Civilization dan Islamiphobia di barat. Dalam pendidikan tentang subjek Islam di institusi perguruan tinggi barat, citra Islam yang anti barat dan agama lain memang sentiasa diberikan penekanan utama. Hal ini menyebabkan sarjana Islam yang berkhidmat di institusi perguruan tinggi barat merasa bertanggungjawab untuk memperbaiki kesalahfahaman ini (Khaled, 2003)

\section{Citra Negatif Islam Dalam Islamiphobia Barat.}

\section{Munculnya Fenomena Islamiphobia}

Islamiphobia ini merujuk kepada rasa fobia (kebimbangan) terhadap Islam baik pada penganutnya, ajarannya, budayanya dan apa saja yang berkaitan dengan Islam. Menurut Pelapor Khas PBB, Islamiphobia berarti : suatu permusuhan dan ketakutan tidak berasas terhadap Islam dan akibat ketakutan atau kebencian pada orang Islam atau mayoritas daripada mereka (Denien, 2006). Definisi yang sama diberikan oleh Laporan Commission on British Muslims and Islamiphobia yang menyatakan bahwa ia merujuk kepada dread or hatred of Islam and, therefore, to fear or dislike all or most Muslims atau irrational fear of Islam or anti-Muslim racism and continuation of antiAsian and anti-Arab racism (Trust, 2011)

Istilah Islamiphobia ini telah ditemui penggunaannya di Perancis oleh Etienne Dinet dan Slima Ben Ibrahim pada 1925 di dalam bukunya "Acces De Delire Islamophobe". Namun begitu, istilah ini tidak popular dan ia juga sama sekali tidak menjadi isu pada waktu itu. Di Amerika, Islamiphobia ini muncul pada 1991 melalui artikel dalam majalah Insight, namun masyarakat tidak ambil peduli dan tidak memberikan apa-apa tanggapan terhadap fenomena Islamiphobia ini (Trust, 2011). Akhirnya istilah Islamiphobia ini semakin popular dan mencapai puncak penggunaannya selepas 11 September 2001 diikuti dengan pengeboman di Madrid pada 11 Maret 2004 dan pengeboman di London pada 7 Juli 2005.

Jadi, dapat dirumuskan bahwa Islamiphobia ini merujuk kepada tanggapan negatif terhadap Islam dalam bentuk diskriminasi pelbagai yang dimotivasikan oleh ketakutan dan kebimbangan terhadap Islam atau umat Islam. Persepsi negatif yang terbina akibat fobia terhadap Islam ini dapat dilihat dalam pelbagai aspek dan ini merangkumi pandangan serong terhadap undang-undang, nilai-nilai dan budaya yang dibawa oleh Islam. Persepsi negatif ini disahkan dengan Laporan Runnymede di London bertajuk Islamiphobia: A Challenge for Us' All menyatakan bahwa

Islam is perceived as a monolithic block, static and unresponsive to change; it is viewed as separate and "other"; it does not have values in common with other cultures, is not affected by them and does not influence them. Islam is seen as inferior to the West; it is considered barbaric, irrational, primitive and setidak ist;

JAS-PT

ISSN $2580-5339$

ISSN $2620-5718$

Volume 2

Nomor 1

JULI 2018

Hal $27-38$

FORUM DOSEN INDONESIA
Islam is seen as violent, aggressive, threatening, and supportive of terrorism and engaged in a "clash of civilizations." (Trust, 2011)

Rumusan yang dibuat Runnymede ini mengesahkan bahwa Islam telah disalahfahami secara serius oleh banyak pihak terutamanya masyarakat bukan Islam di barat. Sehubungan dengan itu, persepsi yang salah ini perlu diperbaiki segera untuk memastikan Islam yang menjadi rahmat sekalian alam ini difahami atau tidak disalah fahami. Sesungguhnya, pertanggungjawaban ini mestilah dipikul oleh setiap individu 
Muslim termasuk institusi-institusi, badan-badan dan perserikatan Islam.

\section{Orientalisme Klasik sebagai pengasas Islamiphobia}

Fakta sejarah menunjukkan bahwa sebelum tercetusnya peristiwa 11 September, hubungan antar umat Islam dengan kuasa barat tidak harmonis. Fenomena Islamiphobia memang telah berakar dalam pemahaman masyarakat barat tentang Islam. la menjadi agak sulit untuk diatasi sama ada di peringkat intelektual ataupun dasar-dasar politik. Mengikut Mohammad Samiei (2009) Linda Edvardsson dan Edward Said; penerusan Islamiphobia bertepatan dengan idealisme Orientalisme klasik boleh dilihat dalam beberapa perkara;

Pertama, wujudnya binari antara Islam dan barat. Keduanya adalah dua entiti berbeza, di mana barat lebih maju berbanding Islam. Linda Edvardsson menegaskan bahwa ;

Islamophobia is evident when Muslims are perceived as something that does not belong to (the superior) us rather something that has connotations as the other. The notion of US versus THEM is therefore integrated in a way where Muslims and/or Islamic affiliations are etidak cluded from the dominant discourse, thus, to some etidak tent based upon the Orientalist View. (Edvardsson 2008)

Hal ini bertepatan dengan apa yang ditegaskan oleh Edward W. Said;

The general basis of Orientalist thought is an imaginative and yet drastically polarized geography dividing the world into two unequal parts, the larger, "different" one called the Orient, the other, also known as "our" world, called the Occident or the West...There are, of course, many religious, psychological, and political reasons for this, but all of these reasons derive from a sense that so far as the West is concerned, Islam represents not only a formidable competitor but also a latecoming challenge to Christianity. (Edward, 1997)

Menurut Edward Said, walaupun Islamophobia coba ditonjolkan sebagai ide baru di zaman modern ini, tapi hakikatnya ide ini berasaskan kepada ideologi orientalis klasik ; ever since the Middle Ages and some part of the Renaissance in Europe, Islam was believe to be demonic religion of apostasy, blasphemy, and obscurity (Edward, 1997) Hal ini turut diakui oleh Linda Edvardsson yang menyatakan bahwa;

The fantasy about the Orient functioned as a free zone where the Western everyday life....was out of order...Today is Islam often a symbol of fanaticism, terrorism and the patriarchal, in the 1940s more of a etidak otic framing - a kind of side-scene that signalled something different and remote. (Edvardsson 2008) Kedua, agama menjadi faktor terpenting berlakunya pertentangan antara tamadun Islam dan barat. la perlu dipandang secara dualistik ( binari antara kita dan mereka).Edvardsson, 2008)

From feminism to racism, from nationalism to Nazism, from Martidak ism to the Cold War, religion lies in one way or another at the core of the dualistic ideology. In the course of the West and Islam dualism, the role of religion is even more decisive. Islam is portrayed as a holistic religion with a rigid legal and political system. Islam is a given not a choice. It captures the whole identity of its believers. Thus studying religion will suffice to illustrate the whole civilisation. All the completidak ity of Muslim minds and attitudes is dismissed by the dualist; rather he chooses to follow his own reading as a direct method of interpreting the Quran, of course, usually in adualistic paradigm.

Ketiga, Islam dikatakan sebagai agama yang fanatik, tidak rasional dan wajib diperangi oleh barat.

JAS-PT
JURNAL ANALISIS SISTEM PENDIDIKAN TINGGI ISSN $2580-5339$ elSSN $2620-5718$ Volume 2 Nomor 1 JULI 2018 Hal $27-38$

FORUM DOSEN INDONESIA 
Islam is uncivilised, primitive and therefore dangerous, threatening our way of life, our culture, our civilisation and our hard and then soft power. This principle was clearly explained by Huntington, who followed Schmitt's philosophy. To their view, since Islam is the enemy, first and foremost, the West has to fear it and think about some central issues like weapons, war and killing. (Edvardsson, 2008)

Masyarakat barat sering melihat Islam sebagai watak agama yang ganas karena ajaran Islam menyatakan demikian;

It is frequently alleged that Muslims use their religion for strategic, political and military advantage rather than as a religious faith and as a way of life shaped by a comprehensive legal tradition...Muslims are assumed to have an instrumental or manipulative view of their religion rather than to be sincere in their beliefs, for their faith is "indistinguishable from a weapon".(Trust, 2011)

la akibat langsung daripada tabiat buruk golongan ekstremis Muslim yang memperlihatkan watak ganas ini. Akibatnya, masyarakat barat membuat generalisasi bahwa Islam adalah agama yang ganas terhadap penganut agama lain.(Edvardsson, 2008)

\section{Islamiphobia Pasca Peristiwa 11 September}

Pertentangan ini diburukkan lagi dengan peristiwa 11/9. Memang menjadi dosa gerakan ekstrimisme atas nama agama Islam yang memburukkan lagi keadaan ini. Apa yang jelasnya, peristiwa 11 September ini, walaupun dinafikan dilakukan oleh al-Qaedah pada mulanya, tetapi dakwaan ini terjawab selepas berlakunya peristiwa bom di Bali 2002. la memang dilakukan oleh al-Qaedah yang berpegang kepada ideologi salafi Jihadis. Bahana terbesar peristiwa 11 September kepada umat Islam dapat dilihat kepada munculnya fenomena Islamiphobia. (Cluck, 2012)

Selepas peristiwa 11 September, George W. Bush telah menghidupkan kembali ideologi orientalisme (neo orientalism). Hal ini ditegaskan oleh Salazar, his (Bush) speech was constructed on stereotypical words and images that are already recognized in more than 20 years of media and popular culture depictions of Arabs as evil, bloodthirsty, animalistic terrorists. (Salazar, 2004) Ucapan politik ini semakin memanaskan lagi jurang perbedaan (binari) antara barat dan Islam (Salazar, 2004). George W. Bush menegaskan : Islamic fundamentalists are ideological extremists who do not believe in free societies and who happen to use terror as a weapon to try to shake conscience of the free world. Dalam kesempatan yang sama, Bush sekali lagi menegaskan bahawa Islam as intolerable, violent and backward and its followers a threat to USA....their grief has turned to anger, and anger to resolution and either they bring their enemies to justice, or bring justice to their enemies, justice will be done.(Merskin, 2004)

The Neo-orientalis ini menjelaskan bahwa Islam adalah ancaman global kepada tamadun barat. Hal ini ditegaskan oleh penasihat utama George W. Bush yaitu Bernard Lewis dan samuel Hutington (Kerboua, 2016). Samuel Hutington dalam suatu karyanya menegaskan bahwa masalah sebenarnya yang terpaksa dihadapi oleh barat

JAS-PT

JURNAL ANALISIS SISTEM PENDIDIKAN TINGGI ISSN $2580-5339$ eISSN $2620-5718$ Volume 2 Nomor 1

JULI 2018

Hal $27-38$

FORUM DOSEN INDONESIA adalah karena faktor Islam itu sendiri. Islam mengajar penganutnya untuk menyakini ketinggian tamadun sendiri, walaupun dalam realitas sebenarnya hal yang sebaliknya berlaku, di mana tamadun barat lebih tinggi dibandingkan dengan tamadun Islam. Penegasan akhirnya cukup menggemparkan, apabila ia berkata; The problem for Islam is not the CIA or the U.S. Department of Defense. It is the West, a different civilization whose people are convinced of the universality of their culture and believe that their superior, if declining, power imposes on them the obligation to extend that culture 
throughout the world. (Merskin, 20014)

\section{Salafi Jihadis Sebagai Penyumbang Islamiphobia Semasa}

Andainya paparan orientalis dan media barat yang menyumbang pada wujudnya fenomena Islamiphobia, hal yang sama dilakukan oleh Salafi Jihadis. Mereka bertanggungjawab menyuntik sifat pemusuhan kepada barat dalam kalangan umat Islam. Bahkan, sifat pemusuhan ini telah disertakan dengan aksi keganasan yang menyasarkan kepentingan barat.

Salafi Jihadis adalah berasal daripada wahabisme. Mengikut ahli, gerakan salafi pada hakikat terbagi kepada tiga jenis : Salafi da'wah, politik dan salafi jihadis. Dua salafi yang awal ( dakwah dan politik) mengajak masyarakat berpegang kepada apa yang diamalkan oleh generasi salaf tanpa dan memusuhi tindakan ekstrimisme. Manakala salafi jihadis pula menggunakan pendekatan revolusi-keganasan untuk mencapai maksud mereka. Atas dasar itu, salafi jihadis dianggap sebagai faham neo khawarij bentuk baru yang timbul selepas kematian Syed Qutb (Wiktorowicz, 2005). Mereka memperjuangkan penubuhan negara Islam yang menguatkuasakan undang-undang Islam melalui jalan revolusi. Mereka tidak bertolak ansur dengan sebarang elemen menyimpang seperti bid'ah yang berlaku dalam masyarakat dan akan berusaha menghapuskannya melalui jalan kekerasan (Bin Ali, 2012).

Dalam banyak segi, selain berselisihan dalam masalah jihad, kesemua golongan salafi ini bersetuju dalam beberapa prinsip yang sama. Antaranya, isu kewajiban berpegang pada salaful soleh, konsep takfir dan konsep wala wa baraah. Apa yang boleh difahami dalam ketiga prinsip ini mengandung beberapa intipati utama:

a. Keyakinan bahwa hanya penganut salafi saja sebagai umat Islam sejati dibandingkan dengan penganut bukan salafi. Hal ini karena hanya mereka yang berpegang kepada golongan salaful soleh yang terjamin keaslian Islam. Sementara umat Islam lain dituduh berpegang pada versi Islam yang penuh dengan elemen khurafat dan bid'ah.

b. Fahaman Self Truth Claim di atas diabsahkan lagi dengan amalan takfir. Mereka secara mudah mengkafirkan pihak lawan tanpa berusaha meneliti kekuatan hujah pihak lawan. Bahkan, dalam bentuk yang ekstrim, konsep takfir ini membawa implikasi bahwa pihak lawan dianggap halal darah mereka.

c. Tafsiran Islam perlu dibuat secara literal dan menolak segala bentuk penggunaan akal sebagai alat analisis. Bagi mereka, penggunaan akal hanya akan menyebabkan Islam dipengaruhi oleh akal yang subyektif sifatnya.

d. Konsep wala wa baraah membawa citra pemusuhan abadi antara Islam dengan bukan Islam. Umat Islam sejati tidak dibolehkan untuk cenderung hati bersekutu dengan bukan Islam. Hanya ada satu saja pendekatan untuk berhadapan dengan bukan Islam yaitu jihad qital.

Pihak Arab Saudi memang dimaklumi banyak terlibat mendukung (sponsor) penyebaran wahabi ke seluruh dunia. Dalam banyak hal, mereka memang bertanggunjawab menyebarkan ideologi pemusuhan dengan barat. Apa yang jelasnya, semua sifat self truth claim dan prinsip anti barat yang dinyatakan diatas memang menjadi subjek utama dalam ajaran wahabi yang diajarkan di pusat pengajian Islam tajaan wahabi (Hamid 2009)

Mengikut peneliti modern, hanya setelah munculnya gerakan al- Qaedah dan Daesh, barulah KerajaanArab Saudi mempromosikan kesesatan Salafi Jihadis. Hal ini dilakukan tanpa coba menilai prinsip ajaran wahabi lain yang berperan melahirkan

JAS-PT

JURNAL ANALISIS SISTEM PENDIDIKAN TING ISSN $2580-5339$ eISSN $2620-5718$ Volume 2 Nomor 1

JULI 2018

Hal $27-38$

FORUM DOSEN INDONESIA 
semangat pemusuhan dengan barat (Yusof, 2015)

\section{Bagaimana Penyebaran Salafi Jihadis melalui Daesh Di Perguruan Tinggi Malaysia}

Malaysia, seperti Brunei terkenal sebagai negara yang mengamalkan pendekatan authoritarian yang amat ketat pengawalan dalam soal menetapkan pemahaman agama (rahim, 2008). Hanya mazhab sunni yang diizinkan tersebar. Pengawasan ketat ini dibuat melalui Jabatan Kemajuan Islam Malaysia (JAKIM) dan Jabatan Agama Setiap Negeri. Semuanya diletakkan di bawah pengawasan kementerian dalam negeri dan pihak polisi.

Dalam sejarah Malaysia, terdapat 16 kumpulan ekstrimisme yang berasaskan etnis dan agama yang tersebar. la terdiri dari Tentera Sabilullah (1967), Gerakan al-Arqam (1968), Golongan Rohaniah (1971), Koperasi Angkatan Revolusi Islam Malaysia (1974), Crypto (1977), Kumpulan Mohd Nasir Islam (1980), Revolusi Islam Ibrahim Libya (1985), Kumpulan Jundullah (1987), Kumpulan Mujahidin Kedah (1988) Perjuangan Islam Perak (1993) Jama'ah Islamiyyah (2000 ), Kumpulan al-Maunah (2001), Kumpulan Mujahidin Malaysia ( 2005), Darul Islam (DI)3 Tanzim al-Qaeda Bahagian Asia Tenggara (2013), Tanzim al-Qaeda Malaysia (2014), Briged Khalid alWalid Darul Islam Malizia (DIM) Briged Daulah Islamiah Arakan Daulah Islamiah (2015), Fisabilillah Daulah Islamiah Malaysia (aslam, 2009).

Tetapi kesemuanya telah dihentikan melalui tangkapan oleh pihak polisi. Semuanya telah dipaksa melalui proses pemulihan akidah yang mengambil waktu dua tahun. Akan tetapi justru ditemukan bahwa banyak mantan tahanan polisi yang telah terlibat dalam Daesh.

Data terkumpul hingga tahun 2014, diperkirakan terdapat 420 orang pengikut Daesh telah ditangkap. Secara pecahan terperincinya, golongan ini terdiri daripada golongan muda dalam umur antara 20 hingga 40 tahun. Mayoritasnya terdiri atas pegawai negeri sipil, anggota keselamatan, dan pekerja swasta. Terlalu sedikit pelajar sekolah dan mahasiswa perguruan tinggi yang terlibat (Samuel, 2016).

Berdasarkan realitas saat ini, memang terdapat dosen dan mahasiswa perguruan yang terlibat dengan aktiviti Daesh. Antaranya kasusnya;

Pertama, Dr Mahmud Ahmad dikenal pasti oleh polisi Bukit Aman terlibat dalam aktiviti militan sejak 1990-an ketika belajar di Universiti Islam Antarabangsa di Islamabad, Pakistan. Ketika itu, beliau menerima latihan ketenteraan di kem AlQaedah di Afghanistan. Beliau dikenal pasti telah melatih pengebom berani mati Malaysia, Ahmad Tarmimi Maliki yang melatih 25 askar elit Iraq pada 26 Mei 2014.

Beliau merupakan dosen universitas swasta sebelum diterima sebagai dosen di Universitas Malaya. Mahmud merupakan dosen senior di Jurusan Akidah dan Pemikiran Islam UM yang dikatakan masih bersembunyi di selatan Filipina sejak 22 April 2014. Dua anggota selnya yang termasuk dalam buronan polisi adalah Mohd Najib Husen dari Kota Damansara, Petaling Jaya, dan Muhammad Joraimee Awang Raimee. Mereka bertiga terlibat dalam merekrut dan mengirim rakyat Malaysia menyertai pejuang Kumpulan Negara Islam dan Jajahannya (ISIL) di Syria. Dua yang

JAS-PT

JURNAL ANALISIS SISTEM PENDIDIKAN TINGG ISSN $2580-5339$ eISSN $2620-5718$

Volume 2

Nomor 1

JULI 2018

Hal $27-38$

FORUM DOSEN INDONESIA lain adalah anggota Darul Islam Sabah dan menyertai kumpulan Abu Sayyaf di selatan Filipina. Dr Mahmud dan Mohd Najib berlepas ke selatan Filipina pada 22 April 2014 dan dipercayai telah berbai'ah dengan Amir (ketua) sebuah kumpulan militan di Basilan, Selatan Filipina. Di sana mereka menjalani latihan ketenteraan bersama kumpulan tersebut.

Profesinya sebagai dosen senior memudahkan beliau untuk menarik mahasiswa dalam aktivitas militan. Beliau dianggap sebagai ayah oleh para mahasiswanya di Universitas 
Malaya. Ketika di kampus, beliau tidak pernah menyebarkan fahaman radikal malah bersifat profesional saja, kegiatan akademis semata-mata. Beliau juga ahli dalam bidang perbandingan agama khususnya Bible. Dr Mahmud pernah menjadi tamu dalam rancangan radio dan berkongsi pengalaman tentang keahliannya. Beliau bukan saja merekrut rakyat Malaysia untuk bersama-sama berjuang bersama ISIL bahkan juga merancang menculik bekas mahasiswa yang meninggalkan sel karena mereka tahu banyak perkara mengenai aktivitas militan.

Mahmud dikatakan bertanggungjawab merancang untuk mengadakan rapat antara pemimpin sel dari Asia Timur dan mereka di Selatan di sebuah "rumah perlindungan" di Shah Alam, Selangor yang diserbu polisi pada Mei 2014. Antara lain, rapat sesama pemimpin untuk membincangkan berdirinya sebuah Khalifah Islam dipanggil Daulah Islamiyah Asia Tenggara.

Mereka dikaitkan dengan kumpulan militan yang menjalani latihan teknik menembak di Gunung Arang Para, Kuala Kangsar, Perak pada Disember 2014 selama dua hari. Sebanyak 10 anggota menjalani latihan militan itu sebagai persiapan sebelum terbang ke Syria dan Iraq untuk berjihad. Mereka juga menggunakan kem latihan di Port Dickson. Jumlah mereka dianggarkan 100 orang telah dihantar ke Timur Tengah bersama ISIL.

Kedua, Siti Noor Aishah Atam, mantan mahasiswa S 2 UM ditangkap di bawah Akta Kesalahan Keselamatan (Langkah-Langkah Khas) 2012 (Sosma) dan kini ditahan di penjara Kajang. Hal ini karena beliau memiliki 12 buah buku yang didakwa berkaitan dengan kumpulan pengganas. Beliau menegaskan telah menggunakan buku-buku berkenaan untuk penyelidikan ijazah sarjananya.

Ketiga, penelitian yang dilakukan oleh Mohd Mizan Aslam (2017) dan Azazuddin Mohd Sani (2016) menemukan bahwa peningkatan mahasiswa Malaysia dalam dan luar negeri yang terpengaruh dengan dakyah Daesh. Mahasiswa Malaysia juga dikatakan terpengaruh dengan laman media sosial milik Daesh (Hassan, 2016).

Berdasarkan data yang diperolehi oleh pihak polisi, ternyata Daesh tidak mendapat tempat di Perguruan Tinggi Malaysia. Memang ada kasus penangkapan seorang dosen UM, tetapi Daesh gagal menyebar dengan bebas memasuki perguruan tinggi di Malaysia. Untuk kasus 4 orang mahasiswa perguruan tinggi pula, semuanya mendapat pendedahan Daesh melalui media sosial dan internet (jawhar, 2016). Kegiatan mereka dibuat secara sembunyi-sembunyi, mereka ditangkap apabila pihak polisi mencurigai keaktifan mereka melalui media sosial. Data menunjukkan 90\% rakyat Malaysia yang terpengaruh dengan Daesh karena faktor internet dan media sosial (Yasin, 2017).

\section{Tindakan Kepada Mahasiswa Perguruan Tinggi yang Terlibat dalam Aktivitas Keganasan / Daesh.}

Sebelum dibicarakan dengan lebih mendalam mengenai masalah ini, perlu dilihat bahwa, kasus keterlibatan mahasiswa di Perguruan Tinggi di Malaysia tidaklah begitu banyak, tetapi tetap juga ada keterlibatan dari mahasiswa. Secara umumnya, pihak perguruan tinggi tidak mempunyai undang-undung khusus bagi menangani atau mengambil tindakan terhadap pelaku masalah ini. Walaupun begitu, tidak berarti bahwa perguruan tinggi harus menutup mata dalam menangani permasalahan ini.

Terdapat undang-undang dalam negara yang mengatur atau memberantas masalah ini, antaranya adalah Akta Kesalahan Keselamatan (langkah-langkah Khas) (SOSMA) 2012 yang telah menggantikan Akta Keselamatan Dalam Negeri 1960 (ISA). Akta ini telah disahkan di Parlimen pada 17 April 2012 untuk langkah-langkah khas berkaitan dengan kesalahan keselamatan bertujuan mengekalkan keamanan dan keselamatan

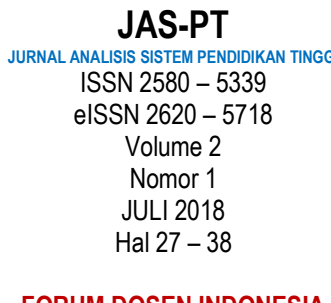

FORUM DOSEN INDONESIA 
bagi hal-hal berkait. Akta ini ditujukan kepada mereka yang melakukan kesalahan baik mahasiswa perguruan tinggi maupun orang awam.

Untuk mengatasi masalah Daesh yang membawa ajaran salafi jihadis ke perguruan tinggi, penguatkuasaan Akta SOSMA ini boleh diambil tindakan kepada mereka yang melakukan:

a. Untuk menyebabkan keganasan terancang terhadap orang atau harta, atau menyebabkan sebilangan besar warganegara takut akan keganasan itu;

b. Untuk membangkitkan perasaan tidak setia terhadap Yang di-Pertuan Agong;

c. Yang memudaratkan ketenteraman awam di dalam Persekutuan atau mana-mana bahagiannya, atau yang memudaratkan keselamatan Persekutuan atau manamana bahagiannya; atau

d. Untuk mendapatkan perubahan, selain dengan cara yang sah, apa-apa jua yang ditetapkan melalui undang-undang.

Dari kandungan undang-undang di atas, jelas menunjukkan bahwa aktivitas yang berkaitan dengan ekstrimis Daesh ini dapat ditindak apabila dilakukan dalam Negara Malaysia. Apabila terdapat penyebaran ajaran ini masuk ke perguruan tinggi, maka langkah yang perlu dan pernah diambil adalah :

Pertama, pihak perguruan tinggi seharusnya mengeluarkan aturan khusus bagi penyebaran ini, termasuk tidak menerima orang sembarangan untuk memberikan pidato maupun mengajar di dalam kampus. Hal ini diutarakan oleh Presiden Unversitas Islam Antarabangsa Malaysia, Tan Sri Dr Rais Yatim (Utusan Borneo Online, 2014)

Kedua, perguruan tinggi harus sentiasa bekerjasama dengan pihak keselamatan negara untuk menghindarkan mahasiswa perguruan tinggi terlibat dalam masalah Daesh. Hal ini disarankan oleh mantan Menteri Pengajian Tinggi Malaysia, Datuk Seri Idris Jusoh (Sinar Online, 2012).

Ketiga, penahanan atau penangkapan. Hal ini sesuai dengan seksyen 4 (1) SOSMA yang tertulis "Seorang pegawai polis boleh, tanpa waran, menangkap dan menahan mana-mana orang yang berkenaan dengannya dia mempunyai sebab untuk mempercayai terlibat dalam kesalahan keselamatan".(SOSMA, 2012).

Berdasarkan kepada peraturan perundangan ini, Ayob Khan Mydin Pitchcay yang menjabat Ketua Penolong Pengarah Bagian Terrorism Cawangan Khas Bukit Aman, sebanyak 19 orang mahasiswa perguruan tinggi pernah ditahan oleh pihak polisi untuk diselidiki keterlibatan mereka terhadap kelompok Daesh ini (Utusan Online 2017). Apabila mereka terbukti bersalah, maka mereka akan dimasukkan ke penjara di bawah akta ini. Sebagai contoh, Siti Noor Aishah Atam, mantan mahasiswa sarjana Universitas Malaya ditangkap di bawah Akta Kesalahan Keselamatan (Langkah-Langkah Khas) 2012 (Sosma) dan kini ditahan di penjara Kajang. Hal ini seperti yang dilaporkan oleh koran arus perdana berita harian (Berita Harian Online, 2017)

Dari penjelasan di atas, jelas bahwa golongan yang cenderung kepada aliran salafi jihadis tidak mendapat tempat di perguruan tinggi. Apabila perbuatan mereka ini

JAS-PT

JURNAL ANALISIS SISTEM PENDIDIKAN TINGG ISSN $2580-5339$ eISSN $2620-5718$

Volume 2

Nomor 1

JULI 2018

Hal $27-38$

FORUM DOSEN INDONESIA terbongkar, maka tindakan dari pihak perguruan tinggi dengan kerjasama pihak keselamatan negara (polisi) akan mengambil tindakan dan seterusnya akan menjatuhkan hukuman jika tersangka terlibat dengan ekstrimis.

\section{Dampak Pendidikan Ideologi Salafi Jihad Dalam pembentukan Islamiphobia}

Kita dapat mengesan pendekatan dan kurikulum sistem pendidikan salafi jihadis ini melalui paparan sarjana barat (Olidort, 2016) dan terlebih penting lagi, ia dapat dilihat dalam sejumlah majalah Dabiq (Lanemeijer, 2016). Majalah Dabiq ini dikeluarkan 
secara online yang boleh dibaca oleh semua masyarakat seluruh dunia (razak, 2018).

Dalam kurikulum pendidikan Daesh, penekanan utama diberikan kepada pembentukan mindset salafi Jihadis. la menekankan peranan Mindset yang ditanam kepada ahli baru. Mindset (pemikiran kekal yang dibentuk melalui agama) mereka diterapkan dengan elemen kebencian pada barat. Memang maklumat yang doktrinkan masuk ke dalam mindset ahli ini benar, tetapi ia diterapkan bercampur dengan kebencian kepada barat (Milla, 2013).

Mindset atau akidah ini menjadi pemangkin sebarang bentuk pemikiran, sikap dan tindakan manusia. la juga menjadi mekanisme pertahanan yang akan menolak semua ide baru yang masuk. Maklumat ini pula dianggap cocok dengan nilai Islam yang bersifat mutlak dan tidak boleh dilawan karena akan menyebabkan sesorang menjadi kafir.

Dalam proses ini, ahli Daesh doktrin dengan beberapa maklumat seperti; (Hassan, 2009)

a. Konsep tauhid dalam 3 bentuk ( Uluhiyah, Rububiyyah dan Sifatiyyah). Apa-apa yang berlawanan dengan tauhid ini wajib diperangi. Mati karena mempertahankan asas tauhid dianggap sebagai syahid.

b. Memang ada perbedaan antara Islam dan kafir. Orang kafir dianggap pembangkang karena tidak mau menerima Islam walaupun hakikatnya mereka mengetahui kewujudan Allah. Orang kafir bertindak seperti syaitan, walaupun mengetahui kebenaran Islam tetapi tetap enggan menerima, bahkan sebaliknya memusuhi dan membunuh umat Islam.

c. Konsep Takfir, (Bin Ali 2012), tindakan mengkafirkan golongan yang tidak sependapat dengan pemikiran mereka. Implikasinya darah orang yang dikafirkan, termasuk ahli masyarakat awam yang tidak sependapat dengan mereka dianggap sebagai halal. Jadi, bagi mereka diharuskan untuk membunuh lawan dan orang awam yang bersekongkol dengan lawan mereka. Bahkan mereka lebih memilih membunuh sesama Islam daripada membunuh orang bukan Islam sendiri.(Haron, 2013)

d. Ahli akan diperlihatkan dengan peristiwa, bahan bacaan, film, foto yang menunjukkan kezaliman orang kafir pada Islam. Dalam hal ini, kasus penderitaan umat Islam di Afghanistan, Palestin, Iraq, Kashmir akan diberikan.

\section{Penutup}

Sebagai kesimpulan akhir, terbukti bahwa fenomena Islamiphobia saat ini muncul antara lain karena usaha golongan Daesh (Salafi Jihadis) sendiri. la diterapkan melalui sistem pendidikan daesh yang dapat dilihat melalui majalah Dabiq. Hal ini turut diperparah lagi dengan paparan negatif tentang Islam yang dilakukan oleh media barat dan sarjana orientalis modern. Kondisi ini wajib dilakukan reformasi apabila masyarakat dunia ingin hidup aman damai di masa akan datang. Persoalan ini harus diperhatikan oleh pihak perguruan tinggi untuk memastikan bahwa, pendidikan mengenai penularan virus salafi jihadis yang akan membawa dampak negatif kepada dunia yang akhirnya membawa kepada Islamiphobia. Justeru itu, pendidkan mengenai hal ini perlu diperjelaskan kepada mahasiwa untuk menghindari dampak negatif yang tidak diinginkan.

\footnotetext{
JAS-PT

JURNAL ANALISIS SISTEM PENDIDIKAN TINGG ISSN $2580-5339$ elSSN $2620-5718$ Volume 2 Nomor 1 JULI 2018 Hal $27-38$ 
Penelitian ini terhasil daripada grant penyelidikan ditaja (FRGS FP031-2016) di bawah Kementerian Pendidikan Tinggi Malaysia dengan judul Pembinaan Model Wasatiyah Bagi Menanggani Isu Ekstremism Agama Di Malaysia.

\section{Daftar Pustaka}

Ahmad Fauzi Abdul Hamid, (2009), The New Challenges Of Political Islam In Malaysia, Paper presented at the Asia Research Centre Conference on 'New Modes of Governance and Security Challenges in the Asia-Pacific', Murdoch University, Perth, 12 - 13 February 2009.

Ahmad Sauffiyan Abu Hassan (2016), Daesh: Kebangkitan Dan Pengaruh Media Sosial, Jurnal Komunikasi, Jilid 32 (2).

Akta Kesalahan Keselamatan (langkah-langkah Khas) (SOSMA) 2012.

Allen, C. (2001). Islamophobia In The Media Since September 11th, Working Paper For A Conference On Etidak Ploring Islamophobia, Deepening Our Understanding Of Islam And Muslims. 29th May 2009, University Of Westminster, London

Andrea Elizabeth Cluck (2012), Islamophobia In The Post-9/11 United States: Causes, Manifestations, And Solutions, Tesis Sarjana The University Of Georgia.

Bernard Lewis, John Esposito And Gilles Kepel, Tesistem Kedoktoran Untuk University Of Westminster.

Doudou Denien. (2006). International Service For Human Right's Summaries Of Documents For The UN Commission On Human Rights In The 62nd Session And Human Rights Council 2nd Session On Contemporary Forms Of Racism, Racial Ddiscrimination, TIDAK Enophobiaand Related Intolerance. Geneva: UNHCR

H.A.H. Langemeijer, (2016), Don't Hear About Us, Hear From Us : The Role Of ISIS' Online Magazine Dabiq In Shaping Foreign Fighter Motivations, Tesis sarjana, Utrecht University.

Instead. (2004). Commission On British Muslims And Islamophobia. London: Instead.

Jacob Olidort, (2016), Inside The Caliphate's Classroom: Textbooks, Guidance Literature, And Indoctrination Methods Of The Islamic State, Washington: The Washington Institute for Near East Policy.

Jasmine Jawhar (2016), Terrorists' Use Of The Internet: The Case Of Daesh, Kuala Lumpur : SEARCCT.

Khaled Abou El Fadl, (2003), "The Ugly Modern and the Modern Ugly: Reclaiming the Beautiful in Islam," in Progressive Muslims on Justice, Gender and Pluralism, ed. Omid Safi, UK: Oneworld Oxford.

Linda Edvardsson (2008), Islamophobia - Features Of Islamophobia And Strategies Against It, Tesistem Kedoktoran Untuk Malmö University.

Merskin, D. (2004). The Construction Of Arabs As Enemies: Post-September 11 Discourse Quitan Wiktorowicz (2005), A Genealofy Of Radical Islam,

JAS-PT

IURNAL ANALISIS SISTEM PENDIDIKAN TINGG

ISSN $2580-5339$ eISSN $2620-5718$

Volume 2

Nomor 1

JULI 2018

Hal $27-38$

FORUM DOSEN INDONESIA Studies In Conflict And Terrorism, v. 26.

Mirra Noor Milla (2013),The Impact Of Leader-Follower Interactions On The Radicalization Of Terrorists: A Case Study Of The Bali Bombers, Asian Journal Of Social Psychology (2013), 16.

Mohammad Samiei (2009), Neo-Orientalism? A Critical Appraisal Of Changing Western Perspectives. 
Mohd Azizuddin Mohd Sani (2016). ISIS Recruitment Of Malaysian Youth: Challenge And Response, Middle East Institute, May 3.

Mohd Mizan Mohammad Aslam (2009), A Critical Study Of Kumpulan Militant Malaysia, Its Wider Connections In The Region And The Implications Of Radical Islam For The Stability Of Southeast Asia, Tesis Ph.D Untuk Victoria University Of Wellington.

Muhammad Haniff Hassan (2009), Jemaah Islamiyyah Ideology : An Overview,

Dalam (edit Arnauld De Borchagrave) Conflict, Community And Criminality In Southeast Asia And Australia: Assesments From The Field, A Report Of CSIS Transnational Threats Project, Singapore.

Muhd Imran Abd Razak (2018), Analisis Isu-Isu Wanita Dalam Fiqh Jihad Aliran Ekstremisme Agama, Tesis Ph.D Akademi Pengajian Islam universiti Malaya.

Nur Azlin Mohamed Yasin (2017), The Evolution of Online Extremism in Malaysia, $\quad$ A Journal Of The International Centre For Political Violence And Terrorism Research, Volume 9, Issue 7 | July 2017.

Nor Hafizi Yusof, (2015), The Spread Of Salafi Wahabi Influence: A Study In Terengganu, Malaysia, Proceedings Of ICIC2015 - International Conference On Empowering Islamic Civilization In The 21st Century.

Rahimin Affandi Abdul Rahim (2008), Pendekatan Malaysia Dan Indonesia Dalam Menangani Perkembangan Aliran Pemikiran Islam : Satu Analisis Perbandingan, Jurnal JATI, Jabatan Pengajian Asia Tenggara, Fakulti Sastera, UM, V. 13.

Salazar, J. F. (2004), Imperfect Media: The Poetics Of Indigenous Media In Chile. SAGE, London.

Salim Kerboua (2016), From Orientalism To Neo-Orientalism: Early And Contemporary Constructions Of Islam And The Muslim World, Intellectual Discourse.

Said, W. Edward (1997), Covering Islam - How The Media And The Etidak Perts Determine How We See The Rest Of The World. London: Vintage Books.

Sinar Online, sinarharian.com.my/nasional/kpt-pantau-gejala-ekstrimis-di-ipt-1.

The Runnymede Trust. (2011) Islamophobia:A Challenge For All Of Us. London.

Thomas Koruth Samuel (2016), Radicalisation In Southeast Asia : A Selected Case Study Of Daesh In Indonesia, Malaysia And Philippines, Kuala Lumpur : SEARCCT.

UNESCO, (2017) Preventing Violent Extremism Through Education A Guide For Policy-Makers, Paris.

Berita Harian Online tanggal 26 April 2017, bharian.com.my/node/276179

Utusan Borneo Online tanggal 6 November 2014, utusanborneo.com.my/2014/11/06ipt-perlu-ambil-tindakan-pencegahan-elakkegiatan-militan-is

Utusan Online tanggal 1 Maret 2017, utusan.com.my/berita/jenayah/44-mahasiswaterlibat-kumpulan-keganasan-1.452268

JAS-PT

JURNAL ANALISIS SISTEM PENDIDIKAN TINGG

ISSN $2580-5339$

eISSN $2620-5718$

Volume 2

Nomor 1

JULI 2018

Hal $27-38$

FORUM DOSEN INDONESIA 
JAS-PT

JURNAL ANALISIS SISTEM PENDIDIKAN TINGG

ISSN $2580-5339$

eISSN $2620-5718$

Volume 2

Nomor 1

JULI 2018

Hal $27-38$

FORUM DOSEN INDONESIA 